\title{
HIGIENE DAN SANITASI KANTIN SEKOLAH DASAR
}

\author{
Aliefiyah Na'imatul Azizah', Merrisa Ayu Oktanova ${ }^{2}$ \\ 1Universitas Airlangga Program Studi Kesehatan Masyarakat PSDKU Banyuwangi \\ ${ }^{2}$ Puskesmas Mojopanggung Kabupaten Banyuwangi \\ Jalan Wijaya Kusuma No.113 Banyuwangi, Jawa Timur \\ Email: aliefiyah.naimatul-2014@fkm.unair.ac.id
}

\begin{abstract}
Hygiene and Sanitation of Primary School Canteen. Snacks food in the canteen become school children's needs of additional intake while in school. Snacks food become routinely consumed by school children's because it is one of the providers of food in the school environment. School canteen in providing snacks food should be able to pay attention to hygiene and sanitation. Hygiene and food sanitation play an important role because if the hygiene and sanitation of food in bad processing then it can lead to disease. The purpose of this research is to know the hygiene and sanitation of 22 primary school canteens in the working area of Puskesmas Mojopanggung in 2018. The method used in this research is descriptive and research design is observational. There are 5 variables that become the assessment in this research that is location; building; and environmental hygiene, sanitation facilities, personal hygiene of food handlers or sellers, food security, and health promotion tools. The result of assessment of location, building and environmental cleanliness variables is $74,75 \%$, sanitation facility variable equal to $65,4 \%$, personal hygiene variable food handler or seller equal to $73,5 \%$, food security variable equal to $77,8 \%$, and means of health promotion by $60 \%$. Category of health promotion means to be one category that does not meet the requirements, while the other four variables get the medium category. In general, 5 variables in the hygiene and sanitation of 22 primary school canteens in Puskesmas Mojopanggung in 2018 were medium category with percentage of $70.29 \%$.
\end{abstract}

Keyword : Hygiene; Sanitation; Primary school canteen

Abstrak: Higiene Dan Sanitasi Kantin Sekolah Dasar. Makanan jajanan yang ada di kantin menjadi kebutuhan asupan tambahan untuk anak sekolah. Makanan jajanan menjadi rutin dikonsumsi oleh anak sekolah karena merupakan salah satu penyedia makanan yang ada di lingkungan sekolah. Kantin sekolah dalam menyediakan makanan jajanan harus dapat memperhatikan higiene dan sanitasi. Higiene dan sanitasi makanan sangat berperan penting karena apabila higiene dan sanitasi makanan dalam pengolahan yang tidak baik maka dapat memicu timbulnya penyakit. Tujuan dari penelitian ini adalah untuk mengetahui higiene dan sanitasi dari 22 kantin sekolah dasar di wilayah kerja Puskesmas Mojopanggung Tahun 2018. Metode yang digunakan dalam penelitian ini adalah deskriptif dan desain penelitian ini bersifat Observasional. Terdapat 5 variabel yang menjadi penilaian pada penelitian ini yaitu lokasi; bangunan; dan kebersihan lingkungan, fasilitas sanitasi, higiene perorangan penjamah makanan atau penjual, keamanan pangan, dan sarana promosi kesehatan. Hasil penilaian variabel lokasi, bangunan dan kebersihan lingkungan sebesar 74,75\%, variabel fasilitas sanitasi sebesar 65,4\%, variabel higiene perorangan penjamah makanan atau penjual sebesar 73,5\%, variabel keamanan pangan sebesar 77,8\%, dan variabel sarana promosi kesehatan sebesar 60\%. Kategori sarana promosi kesehatan menjadi salah satu kategori yang tidak memenuhi syarat, sedangkan keempat variabel yang lain mendapatkan kategori sedang. Secara keseluruhan pada 5 variabel dalam penilaian higiene dan sanitasi 22 kantin sekolah dasar di wilayah Puskesmas Mojopanggung Tahun 2018 mendapatkan kategori sedang dengan persentase sebesar $70,29 \%$.

Kata Kunci : Higiene; Sanitasi; Kantin sekolah dasar 


\section{PENDAHULUAN}

Higiene makanan merupakan tindakan pencegahan timbulnya penyakit sehingga dapat meningkatkan derajat kesehatan, sedangkan sanitasi adalah penerapan dalam ilmu pengetahuan agar makanan dari awal diproses, disiapkan, dan diperjualbelikan tetap bersih dari kontaminasi fisik, kimia, dan mikroor-ganisme, serta tetap sehat. Higiene dan sanitasi adalah upaya dalam mengendalikan faktor makanan, orang, tempat, dan perlengkapannya yang dapat atau mungkin dapat menimbulkan penyakit atau gangguan kesehatan[1]. Prinsip higiene dan sanitasi makanan yang penting diantaranya perilaku sehat dan bersih pada penjamah dalam mengelola makanan, sanitasi makanan, sanitasi peralatan, dan sanitasi tempat pengolahan makanan. Kualitas higiene dan sanitasi dapat dipengaruhi oleh penjamah makanan dan faktor lingkungan. Agar makanan dapat berfungsi sebagaimana mestinya sehingga kualitas makanan harus diperhatikan. Apabila kualitas higiene dan sanitasi dalam mengelola makanan kurang baik maka dapat menimbulkan kontaminasi pada makanan, sehingga dapat menye-babkan timbulnya suatu penyakit yang berasal dari food borned disease. Kebiasaan hidup bersih dan sehat membantu dalam mengolah dan memproses makanan yang bersih dan sehat ${ }^{[2]}$.

Makanan menjadi salah satu kebutuhan pokok manusia dalam mempertahankan hidupnya. Makanan jajanan adalah makanan dan minuman yang diolah oleh pengrajin makanan di tempat penjualan dan atau disajikan sebagai makanan siap santap untuk dijual bagi umum selain yang disajikan jasa boga, rumah makan atau restoran, dan hotel[1]. Makanan jajanan rutin dikonsumsi oleh anak usia sekolah dengan tujuan untuk asupan tambahan pada saat di sekolah. Berdasarkan UU Republik Indonesia Nomor 36 Tahun 2009 pada Pasal 79 bahwa kesehatan sekolah diselenggarakan untuk meningkatkan kemampuan hidup sehat, sehingga peserta didik dapat belajar, tumbuh, dan berkembang secara harmonis serta menjadi sumber daya manusia yang berkualitas. Makanan jajanan dapat menimbulkan risiko terjadinya penularan penyakit, sehingga anak sekolah menjadi kelompok yang berisiko tinggi tertular penyakit berbasis food borned disease. Penanganan dalam makanan jajanan diantaranya meliputi pengadaan, penerimaan bahan makanan, pencucian, peracikan, pembuatan, pengubahan bentuk, pewadahan, penyimpanan, pengangkutan, dan penyajian makanan atau minuman[1]. Agar makanan dapat berfungsi sebagaimana mestinya sehingga kualitas makanan harus diperhatikan. Makanan jajanan salah satunya adalah kantin sekolah. Kantin adalah sarana yang disediakan oleh pihak sekolah dalam memenuhi kebutuhan pangan di suatu instansi. Kantin merupakan salah satu tempat yang seringkali untuk jajan anak sekolah di lingkungan sekolah. Menurut Keputusan Menteri Kesehatan Republik Indonesia Nomor 942/MENKES/SK/VII/ 2003 tentang pedoman persyaratan higiene sanitasi makanan jajanan bahwa persyaratan meliputi penjamah makanan, peralatan, air; bahan makanan; bahan tambahan; dan penyajian, sarana penjaja, dan sentra pedagang.

Kantin sekolah dasar di wilayah kerja Puskessmas Mojopanggung terdiri dari 22 kantin. Setiap tahun pengamatan pada kantin sekolah dilakukan $2 x$ dalam satu tahun oleh pihak Puskesmas. Form penilaian dan pengamatan higiene dan sanitasi kantin sekolah didapatkan dari Dinas Kesehatan Provinsi Jawa Timur. Tujuan dari penelitian ini adalah untuk mengetahui higiene dan sanitasi dari 22 kantin sekolah dasar di wilayah kerja Puskesmas Mojopanggung Tahun 2018.

\section{BAHAN DAN CARA PENELITIAN}

Jenis penelitian yang digunakan dalam penelitian ini adalah kualitatif dengan rancang penelitian Crossectional. Metode yang digunakan dalam penelitiaan ini adalah deskriptif. Desain penelitian ini bersifat Observasional karena data yang diperoleh dalam penelitian ini dilakukan secara langsung melalui pengamatan dengan bantuan kuesioner. Kuesioner dalam penelitian ini menggunakan form penilaian inspeksi sanitasi kantin yang didapatkan Puskesmas dari Dinas Kesehatan Provinsi Jawa Timur. Populasi dalam penelitian ini adalah kantin sekolah dasar di wilayah kerja Puskesmas Mojopanggung yang berjumlah 22 kantin sekolah tahun 2018. Sampel yang 
digunakan dalam penelitian ini adalah total populasi.

Form inspeksi sanitasi kantin sekolah terdapat 5 penilaian variabel dan terdapat masing-masing sub variabel. Variabel yang menjadi penilaian dalam penelitian ini antara lain lokasi, bangunan, dan kebersihan lingkungan, fasilitas sanitasi, higiene perorangan penjamah makanan atau penjual, keamanan pangan dan sarana promosi kesehatan. Variabel lokasi, bangunan, dan kebersihan lingkungan masing-masing sub variabel mendapatkan nilai 25 apabila dalam kategori baik, mendapatkan nilai 20 apabila sedang, dan mendapatkan nilai 10 apabila kurang. Variabel fasilitas sanitasi, higiene perorangan penjamah makananatau penjual, keamanan pangan, dan sarana promosi kesehatan masing-masing sub variabel mendapatkan nilai 20 apabila dalam kategori baik, mendapatkan nilai 15 apabila dalam kategori sedang, dan nilai 10 apabila dalam kategori kurang. Total nilai maksimal yang bisa didapatkan dari 5 penilaian variabel sebesar 400. Kategori penilaian inspeksi sanitasi kantin sekolah terdapat 3 penilaian yaitu Memenuhi syarat apabila persentase mencapai $80 \%-100 \%$, sedang apabila mencapai $61 \%-79 \%$, dan tidak memenuhi syarat apabila mencapai persentase $<60 \%$.

\section{HASIL PENELITIAN DAN PEMBAHASAN}

Tabel 1. Hasil Pemeriksaan 22 Kantin Sekolah Dasar dari nilai lokasi, bangunan, dan kebersihan lingkungan kantin sekolah

\begin{tabular}{ccccc}
\hline No & \multicolumn{1}{c}{ Aspek dan Indikator Penilaian } & Total Nilai & Nilai Maksimal & Persentase \\
\hline 1. & $\begin{array}{l}\text { Lokasi, bangunan dan kebersihan lingkungan } \\
\text { a. Halaman bersih, rapi, kering, dan jauh dari }\end{array}$ & 460 & 550 & $84 \%$ \\
$\quad \begin{array}{l}\text { sumber pencemaran } \\
\text { b. Konstruksi bangunan kuat, aman, dan } \\
\quad \text { permanen }\end{array}$ & 380 & 550 & $69 \%$ \\
& $\begin{array}{l}\text { c. Tempat penyimpanan makanan dalam } \\
\quad \text { keadaan tertutup, bersih dan bebas lalat. }\end{array}$ & 405 & 550 & $74 \%$ \\
& $\begin{array}{l}\text { d. Peralatan makan dan masak terbuat dari } \\
\text { bahan yang aman dan bersih. }\end{array}$ & 400 & 550 & $72 \%$ \\
$\quad$ Kategori : Sedang & & & $74,75 \%$ \\
\hline
\end{tabular}

Penilaian pertama adalah penilaian lokasi, bangunan, dan kebersihan lingkungan kantin sekolah. Apabila kantin sekolah dalam masing-masing sub variabel terpenuhi, maka bisa mendapatkan nilai maksimal dengan kategori baik sebesar 25. Berdasarkan pada tabel 1 menunjukkan bahwa persentase dari variabel lokasi, bangunan dan kebersihan lingkungan sebesar $74,75 \%$ dengan hasil kategori sedang. Penilaian pada masingmasing sub variabel dengan persentase yang paling terendah dari hasil pemeriksaan 22 kantin sekolah adalah sub variabel konstruksi bangunan kuat, aman, dan permanen sebesar $69 \%$ dengan total nilai 380 dari nilai maksimal 550. Kantin sekolah dari 22 kantin yang ada, sebanyak 7 kantin sekolah yang masih belum memiliki bangunan kuat, aman, dan permanen. Kantin sekolah yang masih belum memiliki bangunan kuat, aman, dan permanen menggunakan halaman sekolah yang memang sudah disiapkan untuk tempat menjajakan makanan dengan diberi meja panjang. Makanan jajanan yang dijajakan dengan sarana penjaja, konstruksinya harus dibuat sedemikian rupa sehingga dapat melindungi makanan dari pencemaran. Konstruksi sarana penjaja harus memenuhi persyaratan yaitu mudah dibersihkan, tersedia tempat untuk air bersih, penyimpanan bahan makanan, penyimpanan makanan siap jadi atau siap disajikan, penyimpanan peralatan, tempat cuci (alat, tangan, bahan makanan), dan tempat sampah[1]. Berdasarkan hasil pengamatan yang telah dilakukan bahwa 7 kantin sekolah yang masih belum memiliki bangunan kuat, aman, dan permanen melakukan pengolahan makanan di satu tempat tersebut. Selain itu, terdapat 7 kantin sekolah yang masih belum memenuhi persyaratan konstruksi sarana 
penjaja sesuai dengan Keputusan Menteri

Fasilitas sanitasi

Kesehatan nomor 942 Tahun 2003.

Tabel 2. Hasil Pemeriksaan 22 Kantin Sekolah Dasar dari nilai fasilitas sanitasi kantin sekolah

\begin{tabular}{clccc}
\hline No & \multicolumn{1}{c}{ Aspek dan Indikator Penilaian } & Total Nilai & Nilai Maksimal & Persentase \\
\hline 2. & & & \\
& $\begin{array}{l}\text { Fasilitas sanitasi } \\
\text { a. Tersedia sumber air bersih memenuhi } \\
\text { syarat kesehatan untuk pengelolaan }\end{array}$ & 325 & 440 & $74 \%$ \\
$\quad \begin{array}{l}\text { makanan } \\
\text { b. Pembuangan air kotor dari dapur tidak }\end{array}$ & 325 & 440 & $74 \%$ \\
$\quad \begin{array}{l}\text { mencemari lingkungan } \\
\text { c. Tersedia tempat pencucian alat makan yang }\end{array}$ & 220 & 440 & $50 \%$ \\
$\quad \begin{array}{l}\text { terdiri dari 3 bak } \\
\text { d. Tersedia fasilitas cuci tangan (Wastafel) dan } \\
\quad \text { dilengkapi dengan sabun }\end{array}$ & 235 & 440 & $53 \%$ \\
$\quad \begin{array}{l}\text { e. Tersedia tempat sampah basah kering, } \\
\text { tertutup dan kedap air }\end{array}$ & 335 & 440 & $76 \%$ \\
$\quad$ Kategori : Sedang & & & $65,4 \%$ \\
\hline
\end{tabular}

Penilaian kantin sekolah yang kedua adalah fasilitas sanitasi, apabila kantin sekolah sudah memenuhi syarat dengan kategori baik maka bisa mendapatkan nilai maksimal sebesar 20. Berdasarkan tabel 2 menunjukkan bahwa persentase dari variabel fasilitas sanitasi sebesar 65,4\% dengan kategori sedang. Penilaian pada masing-masing sub variabel dengan persentase terendah yaitu tersedia tempat pencucian alat makan yang terdiri dari 3 bak sebesar 50\%, yang kemudian urutan persentase terendah kedua adalah tersedia fasilitas cuci tangan (Wastafel) dan dilengkapi dengan sabun yang memperoleh persentase 53\%. Berdasarkan dari hasil pengamatan dan penilaian bahwa 7 kantin sekolah yang tidak memiliki bangunan kuat, aman, dan permanen secara otomatis tidak memiliki tempat pencucian alat makan dan fasilitas cuci tangan (wastafel) yang dilengkapi dengan sabun. Tetapi, kantin sekolah yang sudah memiliki bangunan kuat, aman, dan permanen juga belum tentu memiliki fasilitas tempat pencucian alat makan dan wastafel.

Hampir sebagian kantin sekolah yang telah memiliki bangunan kuat, aman, dan permanen tidak memiliki fasilitas tersebut. Para pemilik penjaja makanan ada yang mencuci peralatan makan di kamar mandi siswa, dibawa pulang kembali, dan di wastafel yang tidak berada satu lokasi dengan bangunan kantin sekolah. Merujuk pada Keputusan Menteri Kesehatan Republik Indonesia Nomor: 942/MENKES/ SK/VII/2003 tentang pedoman persyaratan higiene sanitasi makanan jajanan bahwa untuk bangunan sarana penjaja harus memenuhi persyaratan, salah satunya terdapat tempat pencucian alat apabila memungkinkan dipisah dari tempat pencucian bahan pangan. Kantin atau warung sekolah yang telah menggunakan peralatan makan maka dicuci dengan air bersih mengalir atau 2 bak yang berbeda dan dengan menggunakan sabun[1]. Proses pecucian terdiri dari 4 tahapan yaitu pembersihan sisa makanan, perendaman, pencucian, dan pembilasan dengan 3 bak pencucian ${ }^{[3]}$.

Higiene perorangan penjamah makanan atau penjual 
Tabel 3. Hasil Pemeriksaan 22 Kantin Sekolah Dasar dari nilai Higiene perorangan penjamah makanan atau penjual

\begin{tabular}{clccc}
\hline No & \multicolumn{1}{c}{ Aspek dan Indikator Penilaian } & Total Nilai & Nilai Maksimal & Persentase \\
\hline 3 & $\begin{array}{l}\text { Higiene perorangan penjamah makanan atau penjual } \\
\text { a. Penjamah makanan bebas dari penyakit } \\
\text { berbasis lingkungan }\end{array}$ & 395 & 440 & $90 \%$ \\
& $\begin{array}{l}\text { b. Tangan selalu dicuci bersih, kuku dipotong } \\
\text { pendek }\end{array}$ & 320 & 440 & $73 \%$ \\
& $\begin{array}{l}\text { c. Selalu memakai alat bantu ( jepit,sendok, } \\
\text { garpu dll ) untuk mengambil makanan }\end{array}$ & 275 & 440 & $63 \%$ \\
& $\begin{array}{l}\text { d. Berpakaian rapi dan menggunakan celemek } \\
\text { Kategori : Sedang }\end{array}$ & 300 & 440 & $68 \%$ \\
\hline
\end{tabular}

Penilaian ketiga adalah penilaian pada higiene perorangan penjamah makanan atau penjual yang terdapat 4 sub variabel. Sub variabel masing-masing mendapatkan nilai 20 apabila kantin sekolah dalam kategori baik. Hasil dari pengamatan 22 kantin sekolah memiliki persentase sebesar 73,5\% dan kategori baik dari penilaian higiene perorangan penjamah makanan atau penjual. Tabel 3 menunjukkan bahwa persentase yang paling terendah adalah penjamah yang selalu memakai alat bantu (jepit, sendok, garpu, dll) untuk mengambil makanan sebesar $63 \%$ dengan total nilai sebesar 275 dari nilai maksimal 440 . Berdasarkan hasil pengamatan dan penilaian bahwa dari 22 kantin sekolah terdapat 9 kantin sekolah yang tidak menggunakan atau menyediakan alat bantu seperti jepit,

sendok, gardu, dan lain sebagainya. Pada saat observasi dilakukan, penjaja makanan atau anak sekolah yang membeli makanan biasanya langsung mengambil makanan tanpa menggunakan alat bantu. Menggunakan atau menyediakan alat bantu untuk mengambil makanan bertujuan untuk meminimalisir terjadinya suatu penyakit karena dapat menjadi sebagai perantara media food borned diseases dengan kontaminan yang jumlahnya kecil. Penjamah makanan jajanan dalam melakukan kegiatan pelayanan penanganan makanan jajanan harus memenuhi persyaratan salah satunya adalah menjamah makanan harus menggunakan alat atau perlengkapan, atau dengan alas tangan ${ }^{[1]}$.

\section{Keamanan pangan}

Tabel 4. Hasil Pemeriksaan 22 Kantin Sekolah Dasar dari nilai Keamanan Pangan

\begin{tabular}{clccc}
\hline No & \multicolumn{1}{c}{ Aspek dan Indikator Penilaian } & Total Nilai & Nilai Maksimal & Persentase \\
\hline 4 & $\begin{array}{l}\text { Keamanan pangan } \\
\text { a. Makanan tidak megandung bahan }\end{array}$ & & \\
$\quad \begin{array}{l}\text { berbahaya ( boraks, formalin, siclamat dll ) } \\
\text { b. Makanan ditutup sehingga tidak dihinggapi }\end{array}$ & 385 & 440 & $88 \%$ \\
$\quad \begin{array}{l}\text { lalat, serangga, debu } \\
\text { c. Makanan yang dijual mengandung nilai gizi }\end{array}$ & 315 & 440 & $72 \%$ \\
& $\begin{array}{l}\text { d. Makanan dalam kemasan atau wadah } \\
\quad \text { berlabel (, PIRT ) tidak kadaluarsa }\end{array}$ & 310 & 440 & $75 \%$ \\
& $\begin{array}{l}\text { e. Makanan dan minuman dimasak sempurna } \\
\text { Kategori : Sedang }\end{array}$ & 370 & 440 & $70 \%$ \\
\hline
\end{tabular}

Penilaian keempat adalah penilaian pada keamanan pangan kantin sekolah yang terdapat 5 sub variabel dan mendapatkan persentase sebesar 77,8\% dengan kategori sedang. Tabel 4 menunjukkan bahwa persentase yang paling terendah adalah makanan dalam kemasan atau wadah berlabel (PIRT) tidak kadaluarsa sebesar
$70 \%$ dengan total nilai sebesar 310 dari nilai maksimal 440. Sebanyak 4 kantin sekolah dari 22 kantin sekolah yang telah dilakukan pengamatan ada yang memiliki makanan dalam kemasan dan kadaluarsa tetapi masih diletakkan di bagian jajanan makanan. Makanan jajanan yang disajikan harus dalam keadaan terbungkus dan tertutup, bersih, 
dan aman bagi kesehatan[1]. Berdasarkan buku pedoman pembinaan Usaha Kesehatan Sekolah (UKS) dijelaskan bahwa makanan dalam kemasan tidak boleh sampai menjadi kadaluarsa. Menurut buku pedoman pembinaan Usaha Kesehatan Sekolah (UKS), tujuan dari makanan dalam kemasan yang tidak boleh sampai menjadi kadaluarsa adalah upaya dalam pengendalian terhadap faktor risiko penyakit yang berasal dari kantin sekolah. Masalah utama keamanan pangan di Indonesia terdapat empat hal diantaranya produk pangan yang tidak memenuhi persyaratan, sarana produksi dan distribusi pangan yang tidak memenuhi persyaratan baik pada industri rumah tangga dan penjual makanan jajanan, kasus penyakit dan keracuan melalui makanan, dan tingkat pengetahuan dan kepedulian konsumen terkait keamanan pangan masih dapat dikatakan rendah[4].

\section{Sarana promosi kesehatan}

Tabel 5. Hasil Pemeriksaan 22 Kantin Sekolah Dasar dari nilai Sarana Promosi Kesehatan

\begin{tabular}{clccc}
\hline No & \multicolumn{1}{c}{ Aspek dan Indikator Penilaian } & Total Nilai & Nilai Maksimal & Persentase \\
\hline 5 & Sarana promosi kesehatan & & & \\
& Ada poster atau banner pesan-pesan kesehatan & 265 & 440 & $60 \%$ \\
& Kategori : Tidak Memenuhi Syarat & & & $60 \%$ \\
\hline
\end{tabular}

Penilaian terakhir adalah penilaian pada sarana promosi kesehatan dengan sub variabel ada poster atau banner pesan-pesan kesehatan. Berdasarkan tabel 5 menunjukkan bahwa persentase variabel sarana promosi kesehatan sebesar 60\% dengan kategori tidak memenuhi syarat. Total nilai yang didapatkan adalah sebesar 265. Pada saat dilakukan pengamatan dan penilaian, terdapat 11 kantin sekolah yang tidak ada poster atau banner pesan-pesan kesehatan. Terdapat ketentuan bahwa setiap sekolah harus melakukan upaya promosi higiene dan sanitasi yang dapat dilaksanakan secara langsung dan dengan situasi serta kondisi di lingkungan sekolah maupun budaya lokal[5]. Upaya promosi higiene dan sanitasi di sekolah yang dilakukan secara langsung misalnya menggunakan media cetak atau media elektronik atau melalui metode penyuluhan dan sosialisasi[5].

\section{Hasil Pengamatan 22 Kantin Sekolah Secara Keseluruhan dari 5 Variabel}

Tabel 6. Hasil secara keseluruhan 5 Variabel dari 22 Kantin sekolah

\begin{tabular}{clc}
\hline No & \multicolumn{1}{c}{ Aspek dan Indikator Penilaian } & Persentase \\
\hline 1 & Lokasi, bangunan dan kebersihan lingkungan & $74,75 \%$ \\
2 & Fasilitas sanitasi & $65,4 \%$ \\
3 & Higiene perorangan penjamah makanan atau penjual & $73,5 \%$ \\
4 & Keamanan pangan & $77,8 \%$ \\
5 & Sarana promosi kesehatan & $60 \%$ \\
& Kategori : Sedang & $70,29 \%$ \\
\hline
\end{tabular}

Tabel 6 menunjukkan hasil pengamatan dari 22 kantin sekolah di wilayah kerja Puskesmas Mojopanggung Banyuwangi dengan kategori sedang. Persentase hasil pengamatan 22 kantin sekolah dengan 5 variabel sebesar $70,29 \%$. Persentase terendah didapatkan dari aspek dan indikator penilaian sarana promosi kesehatan sebesar $60 \%$, yang kemudian urutan kedua adalah fasilitas sanitasi dengan perolehan $65,4 \%$.

\section{KESIMPULAN DAN SARAN}

Higiene dan sanitasi dari 22 kantin sekolah dasar di wilayah kerja Puskesmas Mojopanggung Tahun 2018 mendapatkan kategori sedang dengan perolehan persentase sebesar 70,29\%. Persentase terendah didapatkan dari aspek dan indikator penilaian sarana promosi kesehatan sebesar $60 \%$. Kantin sekolah yang tidak terdapat sarana promosi kesehatan dalam media poster atau banner pesanpesan kesehatan terdiri dari 11 kantin. Hal ini juga dikarenakan masih ada 7 kantin sekolah yang tidak memiliki bangunan secara permanen sehingga tidak adanya 
tempat atau ruang khusus untuk informasi dalam kesehatan makanan yang aman, bersih, dan sehat.

Diharapkan dari pihak sekolah untuk menyiapkan bangunan tersendiri atau bangunan yang tidak terpakai tetapi layak yang aman, kuat, dan permanen untuk kantin sekolah agar meminimalisir kontaminasi secara fisik, kimia, dan mikroorganisme. Selain itu, apabila menyiapkan bangunan yang aman, kuat, dan permanen untuk kantin sekolah maka kantin sekolah dapat memasang informasi terkait pesan kesehatan makanan aman dan sehat di sekitar bangunan kantin. Pihak puskesmas melakukan sosialisasi, monitoring, dan evaluasi terhadap kantin sekolah secara berkala sehingga meskipun sarana promosi kesehatan masih belum terpasang para penjamah makanan dapat menerapkan higiene dan sanitasi sesuai dengan persyaratan.

\section{KEPUSTAKAAN}

1. Keputusan Menteri Kesehatan Republik Indonesia Nomor 942/MENKES/SK/VII/2003, tentang Pedoman Persyaratan Hygiene Sanitasi Makanan Jajanan. Jakarta.

2. Sihite Richard. Sanitasi dan Higiene. 2000. SIC. Surabaya.

3. Peraturan Menteri Kesehatan Republik Indonesia Nomor 1096/MENKES/PER/ VI/2011, tentang Higiene Sanitasi Jasaboga. Jakarta.

4. Fardiaz. Polusi Air dan Polusi Udara. 2000. Polusi Air dan Polusi Udara. Kanisius. Yogyakarta.

5. Keputusan Menteri Kesehatan Republik Indonesia Nomor 1429/MENKES/SK/ XII/2006, tentang Pedoman Penyelenggaraan Kesehatan Lingkungan Sekolah. Jakarta. 
